This is a post-peer-review, pre-copyedit version of an article published in Journal of Business Ethics.

The final authenticated version is available online at: https://doi.org/10.1007/s10551-018-4076-y 
The interactive effect of religiosity and perceived organizational adversity on changeoriented citizenship behavior

\author{
Inam Ul Haq \\ Lahore Business School \\ The University of Lahore \\ Lahore, Pakistan \\ inamulhaq27@gmail.com \\ Dirk De Clercq \\ Goodman School of Business \\ Brock University \\ St. Catharines, Ontario L2S 3A1 \\ ddeclercq@brocku.ca \\ Muhammad Umer Azeem \\ School of Business and Economics \\ University of Management and Technology \\ Lahore, Pakistan \\ umer.azeem@umt.edu.pk \\ Aamir Suhail \\ Faculty of Management Sciences \\ Riphah International University \\ Lahore, Pakistan \\ emailaamir15@gmail.com
}

Paper accepted for publication in Journal of Business Ethics

October 24, 2018 


\title{
The interactive effect of religiosity and perceived organizational adversity on change- oriented citizenship behavior
}

\begin{abstract}
This study adds to business ethics research by examining how employees’ religiosity might enhance their propensity to engage in change-oriented citizenship behavior, as well as how this effect may be invigorated in adverse organizational climates with respect to voluntarism. Two-wave survey data collected from employees in Pakistan show that change-oriented citizenship activities increase to the extent that employees can draw on their personal resource of religiosity and perceive little adversity, measured in this study with respect to whether voluntarism is encouraged. Further, the relative usefulness of religiosity for spurring changeoriented citizenship behavior is particularly strong when employees experience high levels of this organizational adversity, because employees with high religiosity tend to believe that such behavior is more needed in these organizational contexts. For organizations, these results demonstrate that the energy derived from religiosity may stimulate voluntary efforts that invoke organizational change, and the perceived value of such energy allocation is greater when employees perceive organizational environments that provide little encouragement to go beyond formal job duties.
\end{abstract}

Keywords—change-oriented citizenship behavior; religiosity; organizational climate 


\section{Introduction}

Business ethics scholars emphasize the instrumental role of employees who engage in activities that are not formally listed in their job descriptions, or organizational citizenship behaviors (e.g., Kutcher, Bragger, Rodriguez-Srednicki, \& Masco, 2010; Murtaza, Abbas, Raja, Roques, Khalid, \& Mushtaq, 2016; Tang, Sutarso, Wu Davis, Dolinski, Ibrahim, \& Wagner, 2008). In addition to commonly studied forms of such voluntary behavior, which are cooperative in nature and tend to maintain rather than change the organizational status quo (Choi, 2007; Van Dyne, Cummings, \& McLean Parks, 1995), an understudied but important type of voluntary effort pertains to change-oriented citizenship behavior. This type of citizenship behavior reflects “a unique domain of OCB activities ... describing innovative and creative actions by employees that are aimed at bringing about constructive change in the organization” (Vigoda-Gadot \& Beeri, 2012, p. 575). In contrast with helping, compliance, or civic virtue-all behaviors geared toward maintaining existing working arrangements (Choi, 2007; Van Dyne et al., 1995)_ employees who engage in change-oriented citizenship behavior take charge (Morrison \& Phelps, 1999), think outside the box (Vigoda-Gadot \& Beeri, 2012), and are "willing to risk upsetting the status quo and interpersonal relationships, at least in the short term” (LePine \& Van Dyne 2001, p. 328). Change-oriented citizenship behavior can manifest itself in different ways, such as when employees institute new work methods that are more effective for the organization, eliminate redundant procedures, or correct faulty practices (Bettencourt, 2004; Morrison \& Phelps, 1999).

Change-oriented citizenship activities can benefit both the organization and employees themselves, in that they can fuel work motivation and a sense of meaningfulness (Bettencourt, 2004; Campbell \& Im, 2016) and contribute to job performance (Van Dyne \& LePine, 1998). Despite these possible benefits, these activities also are inherently challenging, because other 
organizational members might regard them as disruptive or threatening to their power bases (Barry \& Wilkinson, 2015; Van Dyne et al., 1995). For example, efforts by employees to address problem situations indicate a need to find solutions, and other organizational members might resist if they believe those solutions will eliminate their current status or privileges (LePine \& Van Dyne, 1998; Milliken, Morrison, \& Hewlin, 2003). This resistance might become especially salient when employees are not formally expected to undertake change-oriented activities and instead choose to perform them on a voluntary basis (Choi, 2007; Morrison \& Phelps, 1999).

This conceptual distinction between cooperative and change-oriented forms of extra-role behaviors highlights the need for research that "investigates antecedents of change-oriented OCBs specifically” (Bettencourt, 2004, p. 166). In turn, this study predicts that an enabler of voluntary change-oriented behaviors, despite barriers to them, is employees’ religiosity, or the extent to which faith in a higher being takes a prominent place in people’s lives (De Clercq, Haq, \& Azeem, 2017a; Eaves, Hatemi, Prom-Womley, \& Murrelle, 2008). Employees’ sense of religion can generate various positive outcomes—such as enhanced organizational commitment and job satisfaction (Sikorska-Simmons, 2005), a sense that work is meaningful (Harpaz, 1998), a willingness to work more hours (Snir \& Harpaz, 2004), sustainable consumption-related behaviors (Minton, Kahle, \& Kim, 2015), and citizenship behaviors that are cooperative in nature and seek to maintain the organizational status quo (Kutcher et al., 2010)_but no previous studies investigate how religiosity might inform the likelihood that employees engage in changeoriented citizenship behaviors. This oversight is significant, because it prevents organizations from understanding how the personal energy that employees might derive from their religious faith (Harrington, Preziosi, \& Gooden, 2001; Shinde \& Fleck, 2015) could spill over to the 
identification and implementation of organizational changes that overcome any resistance these disruptive behaviors might evoke (Milliken et al., 2003).

Notably, our interest in the role of religiosity for spurring change-oriented citizenship behavior is not based on the premise that organizations should actively support and leverage religiosity within their ranks. In many countries, it is illegal to adopt religious-based employment practices. Nor do we mean to imply that atheists or people who score low on religiosity might not have an interest in improving the organizational status quo, on a voluntary basis. Instead, we maintain that religiosity is one specific, significant personal resource that might steer employees toward voluntary efforts that change and improve the status quo, with the goal of improving organizational effectiveness. In this regard, it is also important to highlight the empirical context of this study, Pakistan. The arguments developed herein are general and apply to people of many religious faiths, but the focus on religiosity among Muslims is particularly relevant. This religion strongly encourages employees to take the initiative in contributing voluntarily to their organization's well-being (Alhyasat, 2012; Murtaza et al., 2016), including by identifying innovative solutions to organizational problems (Kumar \& Che Rose, 2010). Religiosity might generate a tendency toward conformism in general (Saroglou, Corneille, \& Van Cappellen, 2009), but the principles underlying Islamic faith—and particularly the notion of Zakat, one of the five pillars of the Islamic code of life, which requires people to be proactive in alleviating adverse situations (Olanipekun, Brimah, \& Sanusi, 2015; Zaman, Roudaki, \& Nadeem, 2018)— support the notion that employees should do their utmost to change and improve the organizational status quo, even if these efforts are not included in formal job descriptions.

In addition to examining the link between religiosity and change-oriented citizenship behavior, this study seeks to identify when this personal resource might be most useful in 
spurring change-oriented citizenship behaviors. In particular, we focus on the contingent role of organizational adversity with respect to voluntarism, as reflected in employees’ perceptions that extra-role behaviors are not encouraged in their organization. ${ }^{1}$ The extent to which employees engage in change-oriented citizenship behaviors might diminish when the organizational climate discourages them from going beyond their formal job descriptions (Avery, Tonidandel, Volpone, \& Raghuram, 2010; Pooja, De Clercq, \& Belausteguigoitia, 2016), but we also propose that the personal resource of religiosity might have significant motivational value in such settings for channeling employees' energy levels toward enhanced change-oriented citizenship behavior, explicitly due to the very presence of organizational adversity with respect to voluntarism. In this scenario, their religiosity might convince employees of the need to take up the slack and engage in such behaviors, to compensate for the low chances that their colleagues will do so (Eaves et al., 2008; Kutcher et al., 2010).

\section{Theoretical foundation}

To anchor our arguments about the combined effects of religiosity and perceived organizational adversity toward voluntarism, we draw on two core theories: (1) conservation of resources (COR) theory, which acknowledges the role of anticipated resource gains and losses to explain work behaviors (Hobfoll, 1989, 2001), and (2) self-discrepancy theory, which underscores employees' desire to maintain consistency between their ideal self (i.e., personal values and aspirations) and actual self (i.e., actual behavior) (Higgins, 1987; Lecky, 1961). First, employees are more likely to engage in positive work behaviors when they can leverage their personal resource bases to enjoy additional resource gains, in the form of personal fulfillment for example (Hobfoll, 2001). Religiosity is a personal resource that may spur voluntary change-

\footnotetext{
${ }^{1}$ Such extra-role behaviors might include performing tasks that are not technically required as a part of their job, volunteering for extra assignments for which there is no direct compensation, and, generally speaking, going "above and beyond” the call of duty (Organ, 1988; Podsakoff, MacKenzie, Paine, \& Bachrach, 2000).
} 
oriented behaviors because these behaviors are fulfilling when they align with religious values (Eaves et al., 2008). Similarly, when employees marked by high levels of religiosity go out of their way to improve the organizational status quo with their change-oriented citizenship, they likely experience these efforts as consistent with what they believe they ought to do, according to their own ideals, so they can avoid discrepancies between their ideals and their actual behaviors (Strauman, 1996).

Second, COR theory suggests that employees resist risky activities, such as invoking organizational disruption, to the extent that they anticipate resource losses due to those activities, such as when the surrounding organizational context discourages them (Hobfoll, 2001). Similarly, employees should be reluctant to engage in change-oriented citizenship behavior to the extent that they believe their organization prioritizes formally prescribed job duties, rather than personal initiatives for voluntarism, because they fear that their career prospects might be compromised if they engage in activities that do not align with these priorities (Russo, Guo, \& Baruch, 2014). Conversely, when employees believe that their employer supports and encourages voluntarism, they should be more strongly motivated to engage in change-oriented behaviors, which can generate resource gains in the form of organizational recognition and career advancement (Hobfoll \& Shirom, 2000).

Third, COR theory proposes that the perceived value of applying personal resources to the pursuit of further resource gains is more prominent in adverse work conditions in which such leveraging efforts promise to make a greater incremental difference, such that they appear more meaningful (Hobfoll \& Shirom, 2000). Even if adverse work situations might be resource draining for employees, COR theory predicts that employees become strongly motivated to protect themselves, as well as other organizational members, against this resource drainage, to 
the extent that they can leverage relevant personal energy resources toward behaviors that can contain or even undo the adversity (De Clercq \& Belausteguigoitia, 2017). Similarly, selfdiscrepancy theory suggests that the application of personal energy to certain work behaviors is more salient in organizational contexts in which maintaining consistency (or avoiding discrepancy) between personal values and actual behavior is more relevant and meaningful (Higgins, 1999). Accordingly, a personal resource such as religiosity may spur change-oriented voluntary behavior to a greater extent when employees believe that the organizational climate only focuses on fulfilling preset job duties, creating a greater need for such behavior.

\section{Contributions}

Taken together, we contribute to extant business ethics research by investigating an unexplored driver of change-oriented citizenship behavior (religiosity) and explicating when it is most likely to spur such behavior. Our focus on explaining this behavior aligns with the general acknowledgment that voluntary behaviors, particularly those that are challenging and cannot be taken for granted, are critical manifestations of workplace ethics (Deckop, Cirka, \& Andersson, 2003; De Clercq, Rahman, \& Haq, 2017b; Tang et al., 2008). Previous research indicates how individual factors such as employees’ openness (Miao \& Qian, 2016), learning orientation (Bettencourt, 2004), or promotion focus (Simo, Sallan, Fernandez, \& Enache, 2016) stimulate change-oriented citizenship behaviors, but no studies consider a role of the energy derived from religiosity. Our interest in religiosity as an enabler of change-oriented citizenship also extends previous business ethics research on the role of this personal factor in spurring citizenship that reinforces the organizational status quo (Kutcher et al., 2010), and it aligns with calls to devote more attention to how employees’ personal values, including those informed by religion, may spill over to the workplace and stimulate them to undertake challenging work activities that can 
enhance organizational effectiveness (Choi \& Moon, 2016; De Clercq et al., 2017b; Murtaza et al., 2016).

We also contribute to extant research by investigating the organizational conditions in which leveraging this personal resource into change-oriented citizenship behavior might be most salient. Somewhat counterintuitively, the positive role of religiosity might be especially strong when employees believe that the organizational climate maintains a strict focus on completing formally prescribed job tasks, without leaving room for themselves or their colleagues to go beyond formal job duties (Ehrhart \& Naumann, 2004; George \& Jones, 1997; Schein, 2010). That is, when employees anticipate that their colleagues might not perform any voluntary activities — let alone voluntary activities that are disruptive and invoke change- because their employer does not endorse these activities, the perceived value of allocating personal energy, based on their religion, to change-oriented citizenship behavior should be higher. Such energy

allocation may be perceived as particularly useful in this scenario, thereby generating even more resource gains in the form of personal fulfillment (Hobfoll, 2001) and reinforcing the desire to maintain consistency between the ideal self and actual work behaviors (Higgins, 1999).

\section{Theoretical background and hypotheses}

Change-oriented citizenship behaviors represent a specific form of organizational citizenship that entails the identification and implementation of changes in the organization's work practices, such that they are intended to alter and improve the status quo (Bettencourt, 2004; Choi, 2007; Seppälä, Lipponen, Bardi, \& Pirttilä-Backman, 2012). These activities are valuable for both the organization and their performers. For example, constructive solutions to organizational failures can spur organizational learning (Argyris \& Schon, 1978) and improve competitive advantages (Morrison, 2011). Finding novel solutions to persistent organizational 
problems also can enhance employees’ motivation (Mishra \& Shukla, 2012), job performance (Van Dyne \& LePine, 1998), and career prospects (Seibert, Kraimer, \& Crant, 2001).

Along with these positive outcomes, employees who engage in change-oriented behaviors, beyond their formal job duties, might encounter resistance (Liang, Farh, \& Farh, 2012; Van Dyne \& LePine, 1998). Organizational members may disagree about whether the issues constitute actual problems (Maynes \& Podsakoff, 2014), or they might undermine voluntary efforts to avoid any attributions of problems to themselves (Morrison, 2011). Making changes that alter the status quo also might tarnish employees’ own reputations, if those activities violate current organizational rules or prevent employees from meeting the formal performance requirements that organizational leaders have set for them (Milliken et al., 2003; Scott \& Bruce, 1994). Thus, there is a clear need to understand which factors steer employees toward change-oriented citizenship behaviors, despite these hurdles (Choi, 2007; Kao, 2017; Simo et al., 2016).

Even in the face of growing interest in the antecedents of employees' change-oriented citizenship behaviors (Bettencourt, 2004; Choi, 2007; Morrison \& Phelps, 1999; Seppala et al., 2012), little attention has been devoted to the potentially positive effect of employees' religiosity (Eaves et al., 2008). Following COR and self-discrepancy theory, we explicitly predict that the energy derived from religiosity translates into an enhanced propensity to engage in these positive work behaviors, because the process facilitates additional resource gains in the form of personal fulfillment (Hobfoll, 1989, 2001) and avoids any discrepancy between personal values and actual behavior (Higgins, 1987, 1999).

Moreover, we propose that the value that employees with high religiosity gain from engaging in change-oriented citizenship behavior should be particularly substantial when the 
organizational climate seems to emphasize a strict adherence to preset job obligations, instead of encouraging employees to spend time on extra-role activities (Barry \& Wilkinson, 2015; Byrne, 2005). According to COR theory, such organizational adversity may steer employees away from voluntary change-oriented activities, because they anticipate resource losses in the form of thwarted career advancement if they go beyond formal job duties in these organizational climates (Hobfoll, 2001; Russo et al., 2014). Yet both COR theory and self-discrepancy theory also predict that employees may expect resource gains from leveraging their religiosity to engage in change-oriented citizenship behavior, and that this potential gain should appear particularly valuable in the presence of such organizational adversity. For example, a sense that other organizational members will resist change or avoid suggesting improvements to the organizational status quo reinforces the perception, among employees with high religiosity, that they need to act consistently with their personal values (Higgins, 1999; Hobfoll \& Shirom, 2000) — a sense that "if no one else is doing it, it is even more incumbent on me to take the responsibility, in line with my principles.” Thus, perceived organizational adversity toward voluntarism may have an invigorating, rather than mitigating, effect on the positive relationship between religiosity and change-oriented citizenship behavior.

As we noted previously, the empirical context of this study is the relatively underexplored non-Western context of Pakistan. The theoretical arguments we advance are culturally neutral, but the interplay of religiosity and an organizational climate that does not encourage voluntarism, and its predictive effects on change-oriented citizenship behavior, should be highly relevant in this cultural context. Religion is a significant part of how many Muslims experience their lives, including their behaviors and work practices (Ali, 1992; Hodge, 2002; Khan, Abbas, Gul, \& Raja, 2015). The pillar of Zakat in Islamic faith in particular motivates 
Muslims to take a proactive approach to pinpointing and improving problematic situations (Zaman et al., 2018). At the same time, Muslims exhibit clear variations in the extent to which their religious beliefs inform their work activities (Ali, 2005; Murtaza et al., 2016). Moreover, Pakistani culture is marked by relatively high levels of uncertainty avoidance (Hofstede, Hofstede, \& Minkov, 2010), so some employees might be hesitant to engage in risky work behaviors that upset the status quo or evoke resistance from colleagues. Examining the role of religiosity for spurring change-oriented citizenship behavior, despite this challenge, thus is highly pertinent in this understudied research setting.

From a more general perspective, understanding how Islamic beliefs might evoke positive work behaviors, as well as the circumstances in which this role is more pronounced, is useful, especially considering that Muslim countries are major investors in and customers of many Western countries (Johnson \& Grim 2013). The increasing salience of global competition and religious diversity in workplaces demands that organizations learn about how the personal energy that employees might derive from their religious beliefs could inform their workplace behaviors (Khan et al., 2015; Uddin, 2003). Previous business ethics research has examined several outcomes of the extent to which Muslim employees rely on their religious values in work settings, such as their work involvement (Khan et al., 2015), organizational citizenship behaviors that support the status quo (Murtaza et al., 2016), and helping behaviors targeted at coworkers (De Clercq et al., 2017b). But no studies have investigated this role in spurring change-invoking citizenship behaviors, let alone the circumstances in which this process is most prominent.

The study's theoretical framework is summarized in Figure 1, and the logic underlying its constitutive hypotheses is explained in more detail next.

[Insert Figure 1 about here] 


\section{Religiosity and change-oriented citizenship}

We predict a positive relationship between employees' religiosity and their changeoriented citizenship behavior, which reflects both motivation and ability rationales. First, employees with a strong sense of religion, including Muslim employees, tend to express strong inclinations to undertake work activities that contribute to organizational effectiveness but are not formally listed in their job descriptions, because they perceive that these activities align with their religious values (Ali, 2005; Murtaza et al., 2016; Yousef, 2000). Following the logic of COR theory, the personal resource of religiosity should stimulate voluntary change-invoking citizenship behaviors that improve the organizational status quo, because these behaviors generate further resource gains, in the form of personal fulfillment (Hobfoll \& Shirom, 2000). Similarly, the positive link between employees’ religiosity and change-oriented citizenship behavior can be explained by their desire to avoid any discrepancies between the ideals that they hold based on their religious faith on the one hand and their actual contributions to organizational effectiveness on the other (Higgins, 1999; Strauman, 1996). Religious values thus spur change-oriented citizenship behavior because of the consistency between these values and the ability to make a meaningful contribution to organizational effectiveness by changing and improving the status quo (Ali \& Al-Owaihan, 2008; Batson \& Gray, 1981; Tepper, 2003).

Second, employees' religiosity may act as an energy-enhancing personal resource that enables them to undertake challenging work activities, such as citizenship behaviors that upset the organizational status quo. As mentioned, change-invoking activities often provoke significant resistance and thus consume significant energy, which may discourage employees from undertaking them (Liang et al., 2012; Van Dyne, Ang, \& Botero, 2003). Yet COR theory predicts that employees who can draw from energy-enhancing personal resources have greater 
capabilities to allocate energy toward work behaviors that require discretionary efforts or might be perceived as upsetting or provocative (Hobfoll, 2001). When they can draw from the energy that comes with their religiosity, employees accordingly should be better able to cope with the challenging skepticism that their suggestions for organizational change might evoke (Shinde \& Fleck, 2015). In addition, they should feel more confident that the resource gains associated with their voluntary efforts, such as enhanced personal fulfillment when their suggestions are accepted, are within reach (Bandura, 1997). If employees cannot draw from the positive energy associated with a strong religious faith though, they may be less able to undertake extra-role, change-oriented activities and instead limit themselves to easier, less provocative behaviors (Murtaza et al., 2016; Simo et al., 2016). Thus, religiosity provides employees with energy that is useful to their efforts to identify and implement changes to current work practices, even if these activities are not formally expected, and then to persist in these efforts.

Hypothesis 1: There is a positive relationship between employees’ religiosity and their change-oriented citizenship behavior.

Perceived adversity with respect to voluntarism and change-oriented citizenship behavior

Employees’ perceptions of organizational adversity with respect to voluntarism should have a negative link with their change-oriented citizenship behavior. According to COR theory, unfavorable work situations that threaten resource losses steer employees away from behaviors that otherwise might trigger such resource losses (Hobfoll, 1989, 2001). When employees believe that the organizational climate prioritizes formally prescribed job duties, rather than personal initiatives for voluntarism, they may feel constrained in their freedom to apply their personal skills to different activities, as well as fear that they will be penalized if they become distracted by activities that are not listed in their job descriptions (Ehrhart \& Naumann, 2004; Jain, 2015). This fear may lead them to avoid discretionary efforts to identify and implement 
changes to the organizational status quo, because they are worried such efforts will undermine their career prospects (Choi, 2007; Hobfoll \& Shirom, 2000).

An organizational climate that leads employees to sense no encouragement for work activities beyond their formal job duties also might prompt a perception that their organization is insensitive or disrespectful, which could further reduce employees' willingness to engage in those voluntary behaviors (Byrne, 2005; Kacmar \& Baron, 1999). In particular, even if some employees might like it when there are no expectations beyond their formal job responsibilities, many might feel confined by this condition, because their personal growth and development feel thwarted when they see opportunities that could change the status quo in a positive direction (George \& Jones, 1997; Schein, 2010). In contrast, if the organization seems to encourage taking on extra duties or responsibilities, employees may feel strongly motivated to identify and address organizational failures, which subsequently can contribute to the success of their organization (Kao, 2017; Liang et al., 2012). Ultimately,

Hypothesis 2: There is a negative relationship between employees' perceptions of organizational adversity with respect to voluntarism and their change-oriented citizenship behavior.

\section{Moderating role of perceived organizational adversity with respect to voluntarism}

In turn, we hypothesize that the expected value of employees’ religiosity for spurring change-oriented citizenship behaviors should increase, and not decrease, in conditions marked by high perceived organizational adversity with respect to voluntarism. In this case, employees may find it particularly valuable to leverage the positive energy that resides in their religious beliefs into change-oriented citizenship, because the associated contributions to organizational effectiveness can make a greater incremental difference (De Clercq \& Belausteguigoitia, 2017). Even if this invigorating effect of perceived organizational adversity may seem counterintuitive, 
in light of its hypothesized direct negative effect on change-oriented citizenship behavior, it is consistent with the premises of both COR theory (Hobfoll, 2001) and self-discrepancy theory (Higgins, 1999). To the extent that employees anticipate that their colleagues will not extend themselves to change and improve the organizational status quo—-because the organizational climate prioritizes the completion of formally prescribed job duties instead of personal initiatives for voluntarism—-they might be particularly motivated to invest valuable energy, derived from their personal resource of religiosity, in the voluntary identification and resolution of organizational problem situations (Quinn, Spreitzer, \& Lam, 2012). These change efforts are perceived as strongly needed in this case and thus create even more resource gains in the form of personal fulfillment (Hobfoll, 20001).

Similarly, self-discrepancy theory predicts that perceived discrepancies between personal values and actual behaviors have more salient effects for determining their work activities to the extent that these discrepancies are activated by relevant organizational contexts (Higgins, 1999). When the organizational context reinforces the perceived need to maintain consistency between personally held religion-based values and daily work behaviors—such as when voluntary efforts by other members are unlikely because of a strict organizational climate that focuses on meeting in-role job expectations instead of voluntarism—-their religiosity should offer more motivational value and spur voluntary efforts to change and improve the organizational status quo.

Finally, a stronger sense that the organizational climate does not encourage voluntary behaviors may make it seem more valuable for employees to leverage the energy derived from their religiosity to resolve organizational problems, in anticipation that these efforts may alter this specific aspect of their organizational climate (Byrne, 2005; Jain, 2015). That is, when the organizational climate appears overly controlling and centered on preset job obligations, 
employees who can draw from their personal resource of religiosity may feel strongly motivated to invest their personal energy to find solutions to mitigate or address this form of organizational adversity (De Clercq \& Belausteguigotia, 2017; Hobfoll, 2001). For example, employees might devote personal energy, derived from their religion, to request more flexible organizational procedures for performance appraisals that recognize activities that are not formally included in preset job descriptions, which should have particularly strong value in organizational climates in which voluntarism is not encouraged (Ehrhart \& Naumann, 2004; George \& Jones, 1997). In short, the application of energy derived from religiosity to voluntary activities that change and improve the current organizational situation should be perceived as particularly useful and satisfactory in the presence of perceived organizational adversity with respect to voluntarism.

Hypothesis 3: The positive relationship between employees' religiosity and their changeoriented citizenship behavior is moderated by their perceptions of organizational adversity with respect to voluntarism, such that the relationship is stronger at higher levels of such perceived organizational adversity.

\section{Research method}

Sample and data collection

The study hypotheses were tested with survey data collected from employees in four Pakistan-based organizations that operate in the education, banking, and health sectors. One of the authors leveraged existing professional contacts to identify targeted organizations, and after organizational endorsement for participation, made personal visits to the company sites to distribute surveys to possible participants. The surveys were written in English, which is the official language of higher education and business practice in Pakistan. After completing these surveys, the participants placed them in sealed envelopes and returned them to the same author. Although they learned that the insights generated from the findings would benefit their organization, the respondents did not receive any monetary or other incentive to participate. 
The data collection process entailed two rounds, with a three-week time lag between them. The data were collected at two different points in time, rather than simultaneously, to avoid reverse causality and expectancy biases — that is, the likelihood that participants might respond in ways that are consistent with their prediction of the research hypotheses (e.g., that their religious beliefs "should" steer them toward change-oriented citizenship behaviors). The first survey asked employees to assess their religiosity and their organizational environment in terms of whether it encourages voluntary work behaviors. A second survey, administered three weeks later, asked employees to assess the extent to which they engage in change-oriented citizenship behavior. This time lag was long enough to reduce concerns that employees would remember their responses from the first round but short enough to avoid the possibility that significant organizational events might occur during the study. Each survey featured a personal code, so we could match responses between the two rounds.

The data collected in this study may be subject to social desirability bias, so we applied standard procedures, as recommended and used in similar studies undertaken in Pakistan (e.g., Abbas, Raja, Darr, \& Bouckenooghe, 2014; Butt, Choi, \& Jaeger, 2005; De Clercq et al., 2017a; Murtaza et al., 2016). The cover letters that accompanied the surveys clarified the general purpose of the study, assured participants of complete confidentiality, and mentioned that their participation was entirely voluntary, that their responses would only be accessible to the researchers, that no individual-level data would ever be made public, and that only aggregate information would be available to people outside the research team. Participants were also informed that the surveys included a personal code to enable data matching between the two rounds, without compromising their confidentiality. In addition, participants were explicitly told that there were no correct or incorrect answers and asked to answer the questions as honestly as 
possible, features that further reduce concerns about social desirability bias (Spector, 2006). The letter also included contact information for one member of the research team, in case participants had questions or concerns or wished to share their feedback. Finally, respondents had the chance to withdraw from the study at any point. Although social desirability bias cannot be ruled out completely, we believe these standard procedures diminish this potential concern.

Of the 200 originally distributed surveys, the 133 completed sets represent a response rate of $66 \%$. Among the respondents, $7 \%$ were women, $45 \%$ had a masters degree or higher, and their average organizational tenure was 6 years. The predominantly male sample admittedly might limit the generalizability of the findings to more gender-balanced workplaces, but it reflects the reality of Pakistan, with its male-dominated business culture (Ali \& Syed, 2017; Strachan, Adikaram, \& Kailasapathy, 2015).

Measures

The items for the three focal constructs came from previous research and used five-point Likert scales, ranging from 1 (“strongly disagree”) to 5 (“strongly agree”).

Change-oriented citizenship behavior. A nine-item scale, drawn from previous research (Bettencourt, 2004; Morrison \& Phelps, 1999), measured the extent to which employees undertake voluntary, change-invoking activities. Consistent with Morrison and Phelps (1999), the items were preceded by a statement that asked employees to think about any efforts that they might have undertaken in work activities that go beyond formal job descriptions. ${ }^{2}$ Example items were, "I try to correct faulty procedures or practices," “I try to implement solutions to pressing organizational problems," and "I make constructive suggestions for improving how things operate within the organization” (Cronbach’s alpha $=.91)$.

\footnotetext{
${ }^{2}$ To avoid social desirability bias, the statement mentioned that "during the course of their workday, people might engage in behaviors that are not formally required," and the respondents then rated the different examples.
} 
Religiosity. The measure of employees’ religiosity used a 17-item scale developed by Eaves and colleagues (2008) and applied in previous business research (De Clercq et al., 2017a). Sample items included, "I ask God to help me make important decisions," "My faith in God shapes how I think and act every day," and "I sense God's presence while I work" (Cronbach's alpha $=.93)$

Organizational adversity with respect to voluntarism. To assess employees’ perceptions of organizational adversity with respect to voluntarism, a reverse-coded, eight-item scale measured the extent to which employees believed that their organization supported and stimulated activities that extend beyond their formal job duties (Bolino, Turnley, Gilstrap, \& Suazo, 2010). The items were worded in such a way that lower scores reflected beliefs that their organization prioritized formally prescribed job duties, rather than personal initiatives for voluntarism—-that is, high levels of organizational adversity with respect to voluntarism. For example, employees assessed whether "Simply doing your formally prescribed job duties is not enough to be seen as a good employee in this organization," "Management expects employees to voluntarily take on extra duties and responsibilities that aren't technically required as a part of their job," and "In this organization, the people who are seen as team players are the ones who do significantly more than what is technically required of them” (Cronbach’s alpha $=.79)$.

Control variables. The models included three control variables: employees' gender $(1=$ female), education ( 1 = non-university, 2 = bachelor, 3 = master), and organizational tenure (in years). Previous research suggests that male employees might be more willing to engage in risky change-oriented behaviors that are not formally expected by job descriptions (Choi, 2007), more educated employees might be more confident that their change-oriented activities will be successful (Kao, 2017), and employees with longer tenure might be less likely to undertake 
activities that change the status quo of the organization for which they have worked for so long (Seppala et al., 2012). ${ }^{3}$

In support of the convergent validity of the three focal constructs, a confirmatory factor analysis indicated that each of the measurement items had significant factor loadings on its respective constructs ( $\mathrm{t}>2.0$; Gerbing \& Anderson, 1988). Furthermore, evidence for discriminant validity emerged from the finding that all three construct pairs generated significant differences, in chi-square values $\left(\Delta \chi^{2}{ }_{(1)}>.3 .84\right)$, between a constrained model in which the correlation between the constructs was set to equal 1 and a corresponding unconstrained model in which the correlation could vary freely (Anderson \& Gerbing, 1988).

\section{Results}

Table 1 reports the correlations and descriptive statistics, and Table 2 contains the hierarchical regression results. Model 1 includes the control variables only, Model 2 adds religiosity and organizational adversity with respect to voluntarism ,and Model 3 adds the religiosity $\times$ organizational adversity with respect to voluntarism interaction term, calculated after mean-centering its constitutive components (Aiken \& West, 1991). The F-values indicate that each of the three models is significant $(p<.001)$, and the incremental $\mathrm{R}^{2}$-values reveal that Model 2 explains 11.1\% more variance in change-oriented citizenship behavior than Model 1, and Model 3 explains 2.3\% more than Model 2. We also checked the variance inflation factors for each predictor, and they were all lower than the conservative cut-off value of 5 (Studenmund, 1992), so multicollinearity was not a concern.

[Insert Tables 1 and 2 about here]

\footnotetext{
${ }^{3}$ The regression analyses in Table 2 indicate that only organizational tenure has a significant effect on changeoriented citizenship behavior. Following Becker's (2005) recommendations, we performed a robustness check by reestimating the regression models without the non-significant control variables, and the hypothesis results remained consistent.
} 
In Model 1, employees who have worked for the organization for a longer time are less likely to engage in change-oriented citizenship behavior ( $\beta=-.079, p<.001)$, possibly because they benefit more from the organizational status quo, so they are unlikely to undertake voluntary activities that might change that situation, or else they have had more opportunities to learn that proactive change-oriented behaviors are not rewarded in their organization.

In line with the prediction that the personal energy that employees derive from their religious beliefs stimulates them to undertake challenging, change-invoking activities that are not formally expected from their job descriptions, Model 2 shows that religiosity relates positively to change-oriented citizenship behavior $(\beta=.364, p<.001$, Hypothesis 1$)$. Model 2 also supports a deterring effect of perceived organizational adversity: Employees are less likely to engage in change-oriented citizenship behavior to the extent that they perceive the organizational climate is adverse to voluntarism $(\beta=-.199, p<.05)$, as in Hypothesis 2 .

Model 3 offers support for the hypothesized invigorating effect of perceived organizational adversity with respect to voluntarism on the relationship between religiosity and change-oriented citizenship behavior $(\beta=.222, p<.05)$. The likelihood that increasing levels of religiosity enhance such work behaviors increases to the extent that employees believe the organizational climate does not encourage voluntarism. To clarify the nature of this moderating effect, Figure 2 plots the effects of religiosity on change-oriented citizenship behavior at high and low levels of the moderator, combined with a simple slope analysis (Aiken \& West, 1991). The relationship between religiosity and change-oriented citizenship behavior is significant when perceived organizational adversity with respect to voluntarism is high $(\beta=.513, p<.001)$ but not significant when it is low ( $\beta=.069, \mathrm{~ns})$, in further support of Hypothesis 3.

[Insert Figure 2 about here] 


\section{Discussion}

This study extends extant business ethics research by elaborating how employees’ religiosity_ or the extent to which their religious beliefs are an important part of their lives (Eaves et al., 2008; Kutcher et al., 2010)—influences their propensity to identify and implement changes for organizational improvement, even if their formal job descriptions do not require them to do so. This issue is highly relevant, because personal initiatives that upset the current organizational situation and address problem situations might be beneficial, but they also could be considered provocative and threatening to other organizational members and accordingly be received with great resistance (Liang et al., 2012; Van Dyne et al., 2003). The personal resource of religiosity may help overcome this hurdle, by generating personal fulfillment and creating a sense of consistency between personal values and actual work behaviors through changeoriented citizenship. Moreover, we consider how perceptions of organizational adversity with respect to voluntarism may deter employees from undertaking change-oriented citizenship behavior, but also, and somewhat counterintuitively, serve as a catalyst for employees to apply the personal energy derived from their religious beliefs toward such behavior (Quinn et al., 2012). The empirical findings support these theoretical arguments.

Expending voluntary efforts to change and improve the organizational status quo can contribute to organizational effectiveness, but these efforts also consume significant energy because of the criticism with which the implemented changes might be received. Consistent with the logic of COR theory (Hobfoll, 1989, 2001), this challenge is diminished to the extent that employees can draw from a personal resource, such as religiosity, that increases their motivation to undertake change-oriented activities voluntarily because of the additional resource gains that are generated through personal fulfillment. Similarly, employees marked by high levels of 
religiosity are motivated to undertake change-oriented citizenship behaviors, because changing and improving the organizational status quo is consistent with the values and expectations associated with their religious beliefs (Kutcher et al., 2010; Murtaza et al., 2016). Conversely, to the extent that they stay away from undertaking these behaviors, employees with high religiosity might experience a strong discrepancy between their personal ideals and actual work activities (Higgins, 1999). Finally, employees who can draw from an energy-enhancing personal resource such as religiosity might be more confident that they can successfully counter any negative reactions to the disruptions that the suggested changes might cause (De Clercq et al., 2017a; Shinde \& Fleck, 2015). Therefore, they believe their voluntary efforts will pay off and lead to actual changes (Bandura, 1997).

Further, employees who believe that the organizational climate prioritizes the completion of formally prescribed job duties may fear that they will suffer from resource losses, in the form of less positive career prospects, if they go out of their way to find unsolicited solutions to organizational problems (Barry \& Wilkinson, 2015; Ehrhart \& Naumann, 2004). According to COR theory, this perception reduces their propensity to undertake such activities (Hobfoll, 2001). Yet perhaps the most notable insight from this study is that the beneficial effect of employees’ religiosity for spurring change-oriented citizenship behavior is stronger in the presence of such perceived organizational adversity. That is, leveraging personal energy, informed by religious beliefs, toward productive changes to the organizational status quo appears particularly useful when other members are anticipated not to go out of their way to improve the organizational status quo, due to the organization's strict focus on formally prescribed job duties.

This invigorating effect of perceived organizational adversity aligns with both COR theory and self-discrepancy theory. That is, the anticipated benefits of personal resource 
endowments for stimulating further resource gains—such as in the form of personal fulfillment-increases in the presence of negative, resource-draining work conditions (De Clercq \& Belausteguigoitia, 2017; Hobfoll \& Shirom, 2000). Similarly, the felt discrepancy between personal values and actual behavior when employees with high religiosity do not seek to contribute to their organization's well-being through their change-oriented citizenship is particularly strong in organizational climates that stifle voluntarism, so employees have the opportunity to leverage the energy derived from their religiosity to take up the slack (Higgins, 1999; Lecky, 1961). Thus, this adverse organizational context has a reinforcing effect, stimulating employees to maintain consistency between their religious values and work behaviors. With these novel insights, the current study adds to evidence about the direct impact of organizational context factors on the likelihood of change-oriented citizenship behavior (e.g., Choi, 2007; Kao, 2017). Employees who perceive that the organizational climate does not encourage them to undertake extra duties are more motivated to allocate their energy reservoirs, derived from the personal resource of religiosity, to voluntary activities that change the current organizational situation, because they anticipate greater incremental value from these activities (Higgins, 1999; Hobfoll \& Shirom, 2000).

Notably, the invigorating effect of perceived organizational adversity with respect to voluntarism pertains to the incremental contribution of religiosity for spurring voluntary changeoriented work activities. The findings thus provide organizational leaders with a deeper understanding of the circumstances in which employees’ discretionary energy, due to religious beliefs, is more or less likely to steer them toward these behaviors. The interaction plot in Figure 2 indicates that higher levels of organizational adversity are associated with lower changeoriented citizenship behavior (Hypothesis 2), but the theoretical focus of Hypothesis 3 is on the 
slope differences at different levels of perceived organizational adversity. As the interaction plot and corresponding slope analysis indicates, increasing religiosity spurs the likelihood of changeoriented citizenship behavior to a greater extent when this personal resource is combined with a perception of a constraining organizational environment in which the associated personal energy can be applied meaningfully to voluntary activities that challenge the organizational status quo.

\section{Limitations and future research directions}

Some limitations of this study should prompt further research. First, caution is warranted in terms of causality, particularly with respect to the relationship between perceived organizational adversity and change-oriented citizenship behavior. Employees who implement organizational changes successfully might feel energized (Quinn et al., 2012), leading them to develop beliefs that their organization is open to their suggestions. The conceptual model is anchored in the well-established COR and self-discrepancy theories, and a three-week time lag separated the measures of the independent and dependent variables, but additional studies could apply longitudinal designs with longer time frames to specify the long-term, causal processes that link religiosity and perceptions of the organizational climate with change-oriented citizenship behaviors.

Second, and in a related vein, this study predicts that the positive relationship between religiosity and change-oriented citizenship behavior can be explained by anticipated resource gains in the form of increased personal fulfillment and decreased discrepancy between personal ideals and actual behavior, whereas the negative relationship between perceived organizational adversity and change-oriented citizenship behavior is informed by the desire to avoid resource losses in the form of fears about career advancement. The invigorating effect of perceived organizational adversity is predicated on the premise that the perceived value of applying 
personal energy to voluntary, change-invoking activities—by spurring personal fulfillment and avoiding discrepancies-is greater in work environments that do not encourage voluntarism. However, we did not measure these specific mechanisms directly, so additional studies could explicitly include them—as well as consider other possible mechanisms, such as a sense of work meaningfulness or guilt avoidance--to determine which mechanisms are most prominent.

Third, as a specific personal resource, religiosity instills employees with positive energy that is useful for their voluntary work activities, but other individual drivers of employees' change-oriented citizenship behaviors could be considered too. For example, future research could address the role of workplace spirituality—defined as "the recognition that employees have an inner life that nourishes and is nourished by meaningful work that takes place in the context of community” (Ashmos \& Duchon, 2000, p. 137)—to complement our focus on religiosity or faith in a higher being, as well as investigate the role of employees' psychological capital. In particular, studies might determine whether employees are more likely to find the stamina to engage in change-oriented citizenship behavior to the extent that they feel more confident about their work-related skills, are hopeful that they can find effective solutions to problem situations, have an optimistic mindset, or are resilient to possible resistance to their change-invoking activities (Luthans, Luthans, \& Luthans, 2004). Moreover, change-oriented citizenship behavior might be fueled by a strong passion for work (Baum \& Locke, 2014) or the personality trait of duty orientation (Tangirala, Kamdar, Venkataramani, \& Parke, 2013). Further studies could also assess the invigorating effects of other unfavorable aspects of the organizational context for the relative usefulness of employees' valuable personal resources, such as organizational unfairness (Dbaibo, Harb, \& van Meurs, 2010), dysfunctional organizational politics (Abbas et al., 2014), or authoritarian leadership styles (Li \& Sun, 2015). 
Fourth, two empirical weaknesses of this study stem from the sample, which consisted mostly of men and was small. That is, the results might not generalize to organizations with more balanced gender compositions, and even if smaller samples tend to generate more conservative statistical tests of theoretical relationships-particularly for conceptual models that include interaction effects, as in this study (Bouckenooghe, De Clercq, \& Deprez, 2014)—future research could benefit from collecting larger samples. In related vein, even though our theoretical arguments are not industry specific, it might be useful to investigate the role of industry factors, such as the level of competitive rivalry (Porter, 1996), which arguably could make employees more willing to contribute to organizational effectiveness with change-oriented citizenship behavior and influence their perceived need to leverage their personal religion-based energy for such behavior.

Fifth, as noted, this study’s conceptual arguments are culturally independent, but cultural factors nonetheless might interfere. For example, the influence of religiosity for risky, changeoriented citizenship behaviors should be particularly relevant in a country such as Pakistan that is marked by high levels of uncertainty avoidance (Hofstede et al., 2010). Additional studies could test the conceptual framework across different cultural contexts. In countries that are less risk averse than Pakistan, as well as countries that are more individualistically oriented, employees might be less sensitive to the challenge that their voluntary, disruptive behaviors might be received with great resistance, so the usefulness of leveraging valuable personal resources to support such behaviors might diminish. Cross-country comparisons could assess the relative importance of employees’ personal energy reservoirs for spurring voluntary behaviors that change and improve the organizational status quo, as well as the prominence of different underlying moderators in this process, across different cultural contexts. 


\section{Practical implications}

The personal resource of religiosity and constraining organizational climates collectively influence employees’ propensity to pinpoint and implement solutions to organizational problems. Such change-oriented activities can be very beneficial, but they also may be challengingespecially if these activities are not formally required-because other organizational members could disagree about the effectiveness of the proposed solutions and resist solutions that threaten their reputations if the problems are their responsibility (Choi, 2007; Liang et al, 2012). In light of these challenges, organizational leaders should understand when employees are still willing to undertake voluntary change-oriented activities. In particular, they should avoid creating beliefs among their employees that the organizational climate discourages positive activities beyond job obligations, which may represent a significant source of frustration by limiting employees’ perceived freedom and thwarting their personal development. Rather, organizations should create a culture in which employees are encouraged to go the extra mile to find solutions, even if these efforts are not part of their formal job descriptions. Notable in this regard is that some employees may be reluctant to voice their criticism that the organization does not seem to encourage extrarole behaviors (Ehrhart \& Naumann, 2004; Kacmar \& Baron, 1999), so organizational leaders should proactively identify and address this reluctance. For example, to the extent that an organization's traditions tend to include a strict focus on preset job duties, more open communication channels could be created to help employees express their concerns about being constrained. In the absence of such communication channels, employees’ frustration may translate into missed opportunities for organizational change and improvement.

In some cases though, organizations might not be able to eliminate employees’ beliefs that they should focus only on their formal job duties, such as when their workload is high and 
there is no time for improvisation (Avery et al., 2010; Pooja et al., 2016). This study shows that in these cases, employees who can draw from the personal energy provided by their religion perceive particularly great value in undertaking change-oriented citizenship behaviors in the presence of beliefs about adverse organizational environments. As mentioned at the outset, this finding is not meant to imply that organizations should actively stimulate or leverage religious beliefs, or that atheists or employees who score low on religiosity are not willing or able to change their organization's status quo voluntarily; many factors can promote such behaviors. Instead, this study suggests that organizations should be aware that the positive energy and motivation derived from any personal resource that encourages voluntarism, including religion, can stimulate change-oriented citizenship behavior, particularly in organizational climates in which employees believe that there is a strong focus on meeting preset job obligations.

\section{Conclusion}

With this study, we have sought to contribute to business ethics research by addressing questions of how and when employees’ religiosity informs their propensity to identify and implement changes that improve organizational effectiveness, even if these activities are not listed in formal job descriptions. Religiosity fuels such change-oriented citizenship behavior, especially when employees encounter an adverse situation in which their organization seems to give precedence to preset job duties over personal initiatives for voluntarism. In turn, this research might serve as a platform for continued studies of how organizations can leverage the personal resources of their employee bases effectively, especially to encourage disruptive, change-invoking activities that add to their competitive positioning. 


\section{Compliance with ethical standards}

Conflict of interest: The authors declare that they have no conflict of interest.

Ethical approval: All procedures performed in studies involving human participants were in accordance with the ethical standards of the institutional and/or national research committee and with the 1964 Helsinki declaration and its later amendments or comparable ethical standards. 


\section{References}

Abbas, M., Raja, U., Darr, W., \& Bouckenooghe, D. (2014). Combined effects of perceived politics and psychological capital on job satisfaction, turnover intentions, and performance. Journal of Management, 40, 1813-1830.

Alhyasat, K.M.K. (2012). The role of Islamic work ethics in developing organizational citizenship behavior at the Jordanian Press Foundations. Journal of Islamic Marketing, 3, 139-154.

Aiken, L.S., \& West, S.G. (1991). Multiple regression: Testing and interpreting interactions. Newbury Park, CA: Sage.

Ali, A. (1992). The Islamic work ethic in Arabia. Journal of Psychology, 126(5), 507-519.

Ali, A. (2005). Islamic perspective on management and organization. Cheltenham: Edward Elgar.

Ali, A., \& Al-Owaihan, A. (2008). Islamic work ethic: A critical review. Cross Cultural Management: An International Journal, 15(1), 5-19.

Ali, F., \& Syed, J. (2017). From rhetoric to reality: A multilevel analysis of gender equality in Pakistani organizations. Gender, Work and Organization, 24, 472-486.

Anderson, J.C., \& Gerbing, D.W. (1988). Structural equation modeling in practice: A review and recommended two-step approach. Psychology Bulletin, 1033, 411-423.

Argyris, C., \& Schon, D. (1978). Organizational learning: A theory of action approach, Reading, MA: Addison Wesley.

Ashmos, D.P., \& Duchon, D. (2000). Spirituality at work: a conceptualization and measure. Journal of Management Inquiry, 9,134-145.

Avery, D.R., Tonidandel, S., Volpone, S.D., \& Raghuram, A. (2010). Overworked in America? How work hours, immigrant status, and interpersonal justice affect perceived work overload. Journal of Managerial Psychology, 25, 133-147.

Bandura, A. (1997). Self-efficacy: The exercise of control, Freeman, New York.

Barry, M., \& Wilkinson, A. (2015). Pro-social or pro-management? A critique of the conception of employee voice as a pro-social behaviour within organizational behaviour. British Journal of Industrial Relations; doi: 10.1111/bjir.12114.

Batson, C.D., \& Gray, R.A. (1981). Religious orientation and helping behavior: Responding to one's own or the victim's needs? Journal of Personality and Social Psychology 40, 511-520.

Baum, J.R., \& Locke, E.A. (2004). The relationship of entrepreneurial traits, skill, and motivation to subsequent venture growth. Journal of Applied Psychology, 89, 587-598.

Becker, T.E. (2005). Potential problems in the statistical control of variables in organizational research: A qualitative analysis with recommendations. Organizational Research Methods, 8, $274-289$.

Bettencourt, L.A. (2004). Change-oriented organizational citizenship behaviors: The direct and moderating influence of goal orientation. Journal of Retailing, 80, 165-180.

Bolino, M.C., Turnley, W.H., Gilstrap, J.B., \& Suazo, M.M. (2010). Citizenship under pressure: What's a "good soldier" to do? Journal of Organizational Behavior, 31, 835-855.

Bouckenooghe, D., De Clercq, D., \& Deprez, J. (2014). Interpersonal justice, relational conflict, and commitment to change: The moderating role of social interaction. Applied Psychology: An International Review, 63, 509-540. 
Butt A.N., Choi J.N., \& Jaeger A. (2005 ). The effects of self-emotion, counterpart emotion, and counterpart behavior on negotiator behavior: A comparison of individual-level and dyadlevel dynamics . Journal of Organizational Behavior, 26, 681-704 .

Byrne, Z.S. (2005). Fairness reduces the negative effects of organizational politics on turnover intentions, citizenship behavior and job performance. Journal of Business and Psychology, 20, 175-200.

Campbell, J.W., \& Im, T. (2016). PSM and turnover intention in public organizations: Does change-oriented organizational citizenship behavior play a role? Review of Public Personnel Administration, 36, 323-346.

Choi, B.K., \& Moon, H. (2016). Prosocial motive and helping behavior: examining helping efficacy and instrumentality. Journal of Managerial Psychology, 31(2), 359-374.

Choi, J.N. (2007). Change-oriented organizational citizenship behavior: effects of work environment characteristics and intervening psychological processes. Journal of Organizational Behavior, 28, 467-484.

Dbaibo, D., Harb, C., \& van Meurs, N. (2010). Values and justice as predictors of perceived stress in Lebanese organisational settings, Applied Psychology: An International Review, 59, 701-720.

Deckop, J.R., Cirka, C.C., \& Andersson, L.M. (2003). Doing unto others: The reciprocity of helping behavior in organizations. Journal of Business Ethics, 47, 101-113.

De Clercq, D., \& Belausteguigoitia, I. (2017). The usefulness of tenacity in spurring problemfocused voice: The moderating roles of workplace adversity. Journal of Business and Psychology, 32, 479-493.

De Clercq, D., Haq, I.U., \& Azeem, M.U. (2017a). Perceived threats of terrorism and job performance: The roles of job-related anxiety and religiousness. Journal of Business Research, 78, 23-32.

De Clercq, D., Rahman, Z., \& Haq, I.U. (2017b). Explaining helping behavior in the workplace: The interactive effect of family-to-work conflict and Islamic work ethic. Journal of Business Ethics, doi.org/10.1007/s10551-017-3541-3.

Eaves, L.J., Hatemi, P.K., Prom-Womley, E.C., \& Murrelle, L. (2008). Social and genetic influences on adolescent religious attitudes and practices. Social Forces, 86, 1621-1646.

Ehrhart, M.G., \& Naumann, S.E. (2004). Organizational citizenship behavior in work groups: A group norms approach. Journal of Applied Psychology, 89, 960-974.

George, J.M., \& Jones, G.R. (1997). Organizational spontaneity in context. Human Performance, 10, 153-170.

Gerbing, D.W., \& Anderson, J.C. (1988). An updated paradigm for scale development incorporating unidimensionality and its assessment. Journal of Marketing Research, 25, 186192.

Harpaz, I. (1998). Cross-national comparison of religious conviction and the meaning of work. Cross-Cultural Research: The Journal of Comparative Social Science 32, 143-170.

Harrington, W.J., Preziosi, R.C., \& Gooden, D.J. (2001). Perceptions of workplace spirituality among professionals and executives. Employees Responsibilities and Rights Journal, 13, 155-163.

Higgins, E.T. (1987). Self-discrepancy: A theory relating self and affect. Psychological Review, 94, 319-340. 
Higgins, E.T. (1999). When do self-discrepancies have specific relations to emotions? The second-generation question of Tangney, Niedenthal, Covert, and Barlow (1998). Journal of Personality and Social Psychology, 77, 1313-1314

Hobfoll, S.E. (1989). Conservation of resources. A new attempt at conceptualizing stress. American Psychologist, 44, 513-524.

Hobfoll, S.E. (2001). The influence of culture, community, and the nested-self in the stress process: Advancing conservation of resource theory. Applied Psychology: An International Review, 50, 337-369.

Hobfoll, S. E., \& Shirom, A. (2000). Conservation of resources theory: Applications to stress and management in the workplace. In R.T. Golembiewski (Ed.), Handbook of Organization Behavior (2 ${ }^{\text {nd }}$ ed., pp. 57-81). New York: Dekker.

Hodge, D.R. (2002). Working with Muslim youths: Understanding the values and beliefs of Islamic discourse. Children and Schools, 24, 6-20.

Hofstede, G.H., Hofstede, G.J., and Minkov, M. (2010). Cultures and organizations: Software of the mind. Intercultural cooperation and its importance for survival ( $3^{\text {rd }}$ ed.). New York: McGraw-Hill.

Jain, A.K. (2015). Volunteerism and organisational culture: Relationship to organizational commitment and citizenship behaviors in India. Cross Cultural Management, 22, 116-144.

Johnson, T. M., \& Grim, B. J. (2013). Global religious populations 1910-2010. The World's religions in figures: An introduction to international religious demography. New York: John Wiley \& Sons.

Kacmar, K.M., \& Baron, R. A. (1999). Organizational politics: The state of the field, links to related processes, and an agenda for future research. In G.R. Ferris (Ed.), Research in personnel and human resources management (pp. 1-40). Stamford, CT: JAI Press.

Kao, R.-H. (2017). The relationship between work characteristics and change-oriented organizational citizenship behavior: A multi-level study on transformational leadership and organizational climate in immigration workers. Personnel Review, 46, 1890-1914.

Khan, K., Abbas, M., Gul, A., \& Raja, U. (2015). Organizational justice and job outcomes: Moderating role of Islamic work ethic. Journal of Business Ethics, 126, 236-246.

Kumar, N., \& Che Rose, R. (2012). The impact of knowledge sharing and Islamic work ethic on innovation capability. Cross Cultural Management: An International Journal, 19, 142-165

Kutcher, E.J., Bragger, J.D., Rodriguez-Srednicki, O., \& Masco, J.L. (2010). The role of religiosity in stress, job attitudes, and organizational citizenship behavior. Journal of Business Ethics, 95, 319-337.

Lecky, P. (1961). Self-consistency: A theory of personality. New York, NY: Shoe String Press.

LePine, J.A., \& Van Dyne, L. (1998). Predicting voice behavior in work groups. Journal of Applied Psychology: An International Review, 83, 853-868.

Li, Y., \& Sun, J.-M. (2015). Traditional Chinese leadership and employee voice behavior: A cross-level examination. Leadership Quarterly, 26, 172-189.

Liang, J., Farh, C.I.C., \& Farh, J. (2012). Psychological antecedents of promotive and prohibitive voice: A two-wave examination. Academy of Management Journal, 55, 71-92.

Luthans, F., Luthans, K.W., Luthans, B.C. (2004). Positive psychological capital: Beyond human and social capital. Business Horizons, 47, 45-50.

Maynes, T.D., \& Podsakoff, P.M. (2014). Speaking more broadly: An examination of the nature, antecedents, and consequences of an expanded set of employee voice behaviors. Journal of Applied Psychology, 99, 87-112. 
Miao, C., \& Qian, S. (2016). Does leadership matter? A multilevel investigation of the moderators for the relationship between openness and change-oriented behavior. Journal of Leadership, Accountability and Ethics, 13, 77-89.

Milliken, F.J., Morrison, E.W., \& Hewlin, P. (2003). An exploratory study of employee silence: Issues that employees don't communicate upward and why. Journal of Management Studies, 40, 1453-1476.

Minton, E.A., Kahle, L.R., \& Kim, C.-H. (2015). Religion and motives for sustainable behaviors: A cross-cultural comparison and contrast. Journal of Business Research, 68, 1937-1944.

Mishra, R., \& Shukla, A. (2012). Impact of creativity on role stressors, job satisfaction and organisational commitment. Journal of Organization and Human Behavior, 1, 18-26.

Morrison, E.W. (2011). Employee voice behavior: Integration and directions for future research. Academy of Management Annals, 5, 373-412.

Morrison, E.W., \& Phelps, C.C. (1999). Taking charge at work: Extrarole efforts to initiate workplace change. Academy of Management Journal, 42, 403-419.

Murtaza, G., Abbas, M., Raja, U., Roques, O., Khalid, A., \& Mushtaq, R. (2016). Impact of Islamic Work Ethics on organizational citizenship behaviors and knowledge-sharing behaviors. Journal of Business Ethics, 133, 325-333.

Olanipekun, W.D., Brimah, A.N., \& Sanusi, H.B. (2015). The role of Zakat as a poverty alleviation strategy and a tool for sustainable development: Insights from the perspectives of the Holy Prophet. Arabian Journal of Business and Management Review, 5, 8-17.

Podsakoff, P.M., MacKenzie, S.B., Paine, J.B., \& Bachrach, D.G. (2000). Organizational citizenship behaviors: A critical review of the theoretical and empirical literature and suggestions for future research. Journal of Management, 26, 513-563.

Organ, D. W. (1988). Organizational citizenship behavior: The good soldier syndrome. Lexington, MA: Lexington Books.

Pooja, A.A., De Clercq, D., \& Belausteguigoitia, I. (2016). Job stressors and organizational citizenship behavior: The roles of organizational commitment and social interaction. Human Resource Development Quarterly, 27, 373-405.

Porter, M. E. (1996). What is strategy? Harvard Business Review, November/December, 2-19.

Quinn, R.W., Spreitzer, G.M., \& Lam, C.F. (2012). Building a sustainable model of human energy in organizations: Exploring the critical role of resources. Academy of Management Annals, 6: 337-396.

Russo, M., Guo, L., \& Baruch, Y. (2014). Work attitudes, career success and health: Evidence from China. Journal of Vocational Behavior, 84, 248-258.

Saroglou, V., Corneille, O. \& Van Cappellen, P. (2009). 'Speak, Lord, your servant is listening': religious priming activates submissive thoughts and behaviors. International Journal for the Psychology of Religion, 19, 143-154.

Schein, E.H. (2010). Organisational culture and leadership $\left(4^{\text {th }}\right.$ ed.), Jossey-Bass, San Francisco, CA .

Scott, S. G., \& Bruce, R. A. (1994). Determinants of innovative behavior: A path model of individual innovation in the workplace. Academy of Management Journal, 37, 580-607.

Seibert, S.E., Kraimer, M.L., \& Crant, J.M. (2001). What do proactive people do? A longitudinal model linking proactive personality and career success. Personnel Psychology, 54, 845-874.

Seppälä, T., Lipponen, J., Bardi, A., \& Pirttilä-Backman, A.-M. (2012). Change-oriented organizational citizenship behaviour: An interactive product of openness to change values, 
work unit identification, and sense of power. Journal of Occupational and Organizational Psychology, 85, 136-155.

Shinde, U., \& Fleck, E. (2015). What spirituality can bring to leaders and managers: Enabling creativity, empathy and a stress free workplace. Journal of Organizational Psychology, 15, 101-110.

Sikorska-Simmons, E. (2005). Religiosity and work-related attitudes among paraprofessional and professional staff in assisted living. Journal of Religion, Spirituality \& Aging, 18, 65-82.

Simo, P., Sallan, J.M., Fernandez, V., \& Enache, M. (2016). Change-oriented organizational citizenship behavior: Analysis of antecedents centered on regulatory theory focus at the workplace. International Journal of Organizational Analysis, 24, 261-273.

Snir, R., \& Harpaz, I. (2004). Attitudinal and demographic antecedents of workaholism. Journal of Organizational Change Management, 17, 520-536.

Spector, P.E. (2006). Method variance in organizational research: Truth or urban legend? Organizational Research Methods, 9, 221-232.

Strachan, G., Adikaram, A., \& Kailasapathy, P. (2015) Gender (in)equality in South Asia: problems, prospects and pathways. South Asian Journal of Human Resources Management, $2,1-11$.

Strauman, T.J. (1996). Stability within the self: A longitudinal study of the structural implications of self-discrepancy theory. Journal of Personality and Social Psychology, 71, 1142-1153.

Studenmund, A.H. (1992). Using econometrics: A practical guide. New York: Harper Collins.

Tang, T.L.-P., Sutarso, T., Wu Davis, G M.-T., Dolinski, D., Ibrahim, A.H.S., \& Wagner, S.L. (2008). To help or not to help? The Good Samaritan effect and the love of money on helping behavior. Journal of Business Ethics, 82, 865-887.

Tangirala, S., Kamdar, D., Venkataramani, V., \& Parke, M.R. (2013). Doing right versus getting ahead: The effects of duty and achievement orientations on employees' voice. Journal of Applied Psychology, 98, 1040-1050.

Tepper, B. J. (2003). Organizational citizenship behavior and the spiritual employee. In R. A. Giacalone, \& C. L. Jurkiewicz (Eds.), Handbook of workplace spirituality and organizational performance (pp. 181-190). Armonk, New York: M.E. Sharpe, Inc.

Uddin, S. J. (2003). Understanding the framework of business in Islam in an era of globalization: A review. Business Ethics: A European Review, 12(1), 23-32.

Van Dyne, L., Ang, S., \& Botero, I.C. (2003). Conceptualizing employee silence and employee voice as multidimensional constructs. Journal of Management Studies, 40, 1359-1392.

Van Dyne, L., Cummings, L.L., \& McLean Parks, J. (1995). Extra-role behaviors: In pursuit of construct and definitional clarity. In B. M. Staw, \& L. L. Cummings (Eds.), Research in organizational behavior, vol. 17: 215-285. Greenwich, CT: JAI.

Van Dyne, L., \& LePine, J. A. (1998). Helping and voice extra-role behavior: Evidence of construct and predictive validity. Academy of Management Journal, 41, 108-119.

Vigoda-Gadot, E., \& Beeri, I. (2012). Change-oriented organizational citizenship behavior in public administration: The power of leadership and the cost of organizational politics. Journal of Public Administration Research and Theory, 22, 573-596.

Yousef, D. A. (2000). Organizational commitment and job satisfaction as predictors of attitudes toward organizational change in a non-western setting. Human Relations, 53, 513-537.

Zaman R., Roudaki J., \& Nadeem M. (2018). Religiosity and corporate social responsibility practices: evidence from an emerging economy. Social Responsibility Journal, 14, 368-395. 
Figure 1: Conceptual model

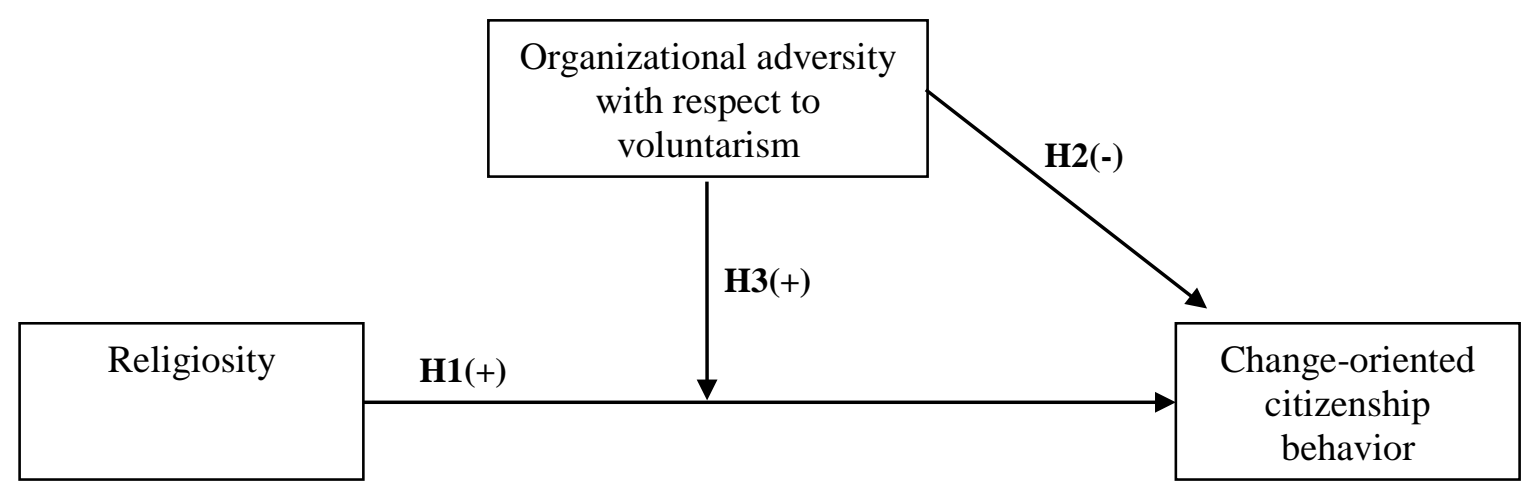


Figure 2: Moderating effect of organizational adversity with respect to voluntarism on the relationship between religiosity and change-oriented citizenship behavior

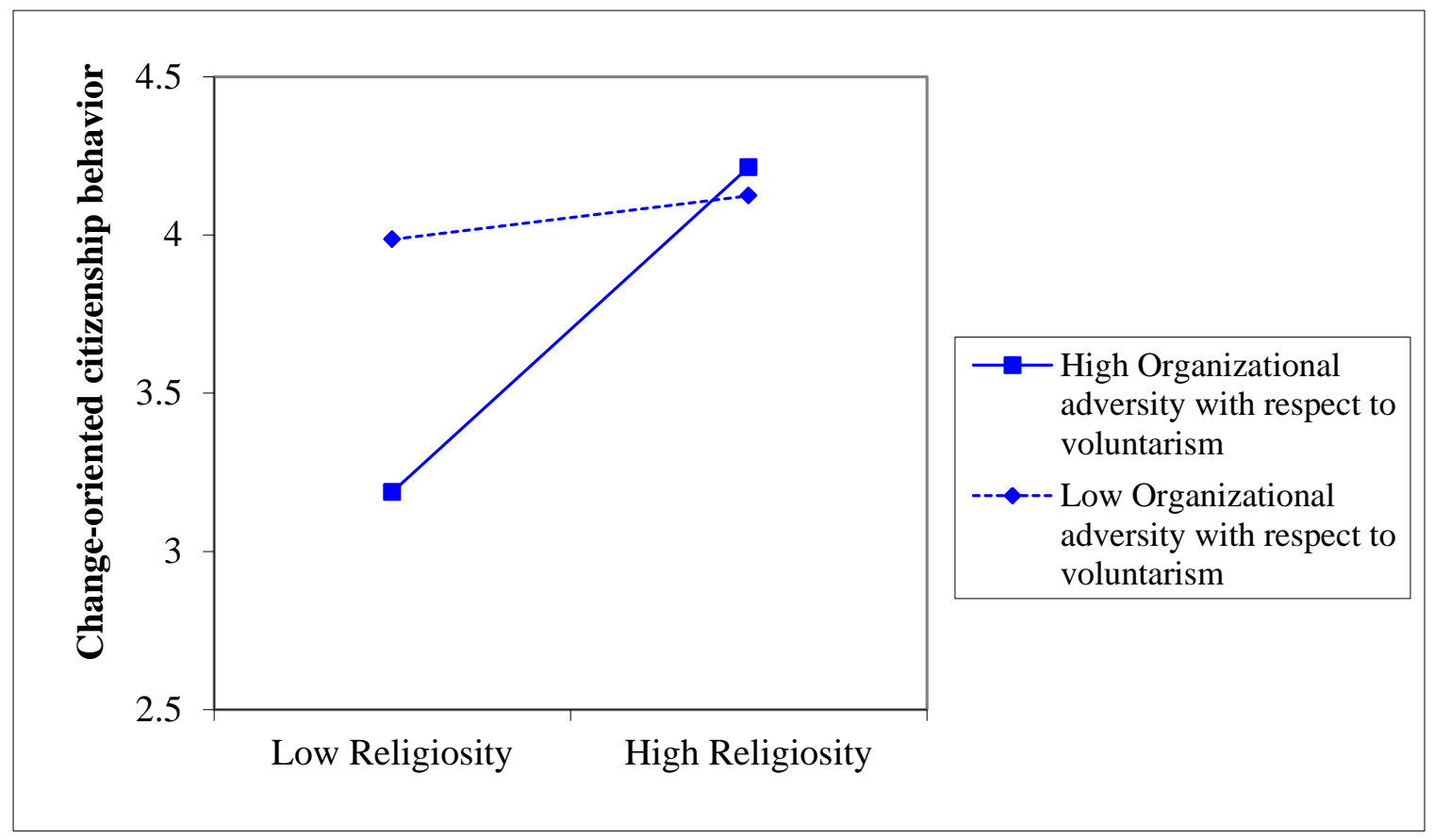


Table 1: Correlation table and descriptive statistics

\begin{tabular}{|c|c|c|c|c|c|c|c|}
\hline & Mean & SD & 1 & 2 & 3 & 4 & 5 \\
\hline 1. Change-oriented citizenship behavior & 3.516 & .771 & & & & & \\
\hline 2. Religiosity & 3.946 & .664 & $.478 * *$ & & & & \\
\hline $\begin{array}{l}\text { 3. Organizational adversity with respect } \\
\text { to voluntarism }\end{array}$ & 2.574 & .647 & -.151 & -.034 & & & \\
\hline 4. Gender & .068 & .252 & .122 & .150 & -.014 & & \\
\hline 5. Education & 2.353 & .654 & .120 & $.198 *$ & .079 & -.054 & \\
\hline 6. Organizational tenure & 6.432 & 4.529 & $-.470 * *$ & $-.468 * *$ & -.075 & $-.265 * *$ & -.162 \\
\hline
\end{tabular}

Notes: $\mathrm{N}=133$.

${ }^{* *} p<.01 ; * p<.05$. 
Table 2 : Regression results (dependent variable: change-oriented citizenship behavior)

\begin{tabular}{lccc}
\hline & Model 1 & Model 2 & Model 3 \\
\hline Gender & .006 & -.048 & -.060 \\
Education & .053 & .018 & .029 \\
Organizational tenure & $-.079^{* * *}$ & $-.058^{* * *}$ & $-.056^{* * *}$ \\
$\mathrm{H}_{1}$ : Religiosity & & $.364^{* * *}$ & $.291^{* *}$ \\
$\mathrm{H}_{2}$ : Organizational adversity with & & $-.199^{*}$ & $-.177^{*}$ \\
$\quad$ respect to voluntarism & & & \\
$\mathrm{H}_{3}:$ Religiosity $\times$ Organizational & & & $.222^{*}$ \\
$\quad$ adversity with respect to & & & \\
$\quad$ voluntarism & $12.343^{* * *}$ & $12.727^{* * *}$ & $11.641^{* * *}$ \\
\hline F-value & .223 & .334 & .357 \\
$\mathrm{R}^{2}$ & & $.111^{* * *}$ & $.023^{*}$ \\
$\mathrm{R}^{2}$ change & & & \\
\hline
\end{tabular}

Notes: $\mathrm{N}=133$ (unstandardized regression coefficients, standard errors in parentheses). ${ }^{* * *} p<.001 ;{ }^{* *} p<.01 ;{ }^{*} p<.05 ;{ }^{+} p<.10$. 